\title{
Korea begins funding projects to catch up with rest of world
}

Seoul. South Korea's Ministry of Science and Technology (MOST) last week announced the first projects in a \$6-billion effort by South Korea to catch up with the technology of Japan and leading Western nations by the beginning of the next century.

The Highly Advanced National Project, than 2,400 billion won by 2001 , matched by a similar contribution from industry.

Last week's announcement covered three of the 14 proposed research areas for the G-7 project: new pharmaceuticals and agrochemicals, new advanced materials and new functional biomaterials. These three topics come under the jurisdiction of MOST. Other G-7 projects, covering such areas as highdefinition television, semiconductors, integrated services and data networks and computerized manufacturing systems, will be announced shortly by other ministries.

More than 20 government institutes, 50 universities and 60 private companies will participate in the projects announced last week. Leading them on the government side is the Korea Institute of Science and Technology more popularly called the G-7 project, is intended to bring South Korea's technology up to a level competitive with the G-7 nations (Japan, United States, Canada, France, Germany, Italy and the United Kingdom) by 2000 (see Nature 354, 176; 1991). The Korean government intends to invest more industry for the three research areas in 1992. Just over half of this budget was assigned last week (see table) with the rest to follow in a few months.

The lion's share of funding goes to development of new drugs and vaccines, in particular antibiotics. Dozens of pharmaceutical companies and several universities will participate in this effort, which is led by KIST (see sidebar) and KRICT. And two new nonprofit government-industry consortia - the New Medicine Development Consortium and the Genetic Engineering Research Consortium - have been established.

Companies such as Hyundai, Samsung and Daewoo are backing the projects to develop advanced materials, such as ceramics, for use in heavy industry, automobile manufacturing and the electronics industry. But so far there is no sign of participation by other nations, as Korean officials had hoped (see Nature 357, 100; 1992).

David Swinbanks

\section{Defence scientist quits Indian post for US academic job}

New Delhi \& Washington. India's chief defence scientist for more than a decade, V. S. Arunachalam, has resigned in frustration over the lack of funding for major defence research and his government's continued reliance on foreign military technology. Arunachalam will be spending the next two years as a visiting professor at Carnegie Mellon University in Pittsburgh, Pennsylvania.

As head of the Defence Research Development Organization(DRDO), Arunachalam oversaw 35 defence laboratories with an annual budget of 11 billion rupees (US $\$ 300$ million) and is credited with the country's rapid progress in defence research. But Arunachalam was criticized for his agency's failure to develop a main battle tank, a project begun in 1975, and a light combat aircraft, begun in the early $1980 \mathrm{~s}$. In response, Arunachalam blames the government for failing to provide sustained support.

$\mathrm{He}$ also blames the government for being in such a hurry that it would rather import defence technology than wait for the homegrown product. As a result, he says, the DRDO has been hurt by "a great deal of invisible foreign lobbying" from companies peddling their wares to India.

But Arunachalam says these internal battles are not the reason behind his resignation, saying instead that he has long wanted "a change of pace". At Carnegie Mellon, he will work on the mechanical properties of materials and on technology transfer. $\mathrm{He}$ intends to take a new position with the Indian government when his sabbatical ends.

K.S. Jayaraman \& Traci Watson 